\title{
Effects of $\mathrm{Ni}$ doping on photocatalytic activity of $\mathrm{TiO}_{2}$ thin films prepared by liquid phase deposition technique
}

\author{
NOOR SHAHINA BEGUM*, H M FARVEEZ AHMED and K R GUNASHEKAR ${ }^{\dagger}$ \\ Department of Studies in Chemistry, Central College Campus, Bangalore University, Bangalore 560 001, India \\ ${ }^{\dagger}$ Department of Instrumentation, Indian Institute of Science, Bangalore 560 012, India
}

MS received 28 December 2007; revised 16 March 2008

\begin{abstract}
The $\mathrm{TiO}_{2}$ thin films doped by $\mathrm{Ni}$ uniformly and non-uniformly were prepared on glass substrate from an aqueous solution of ammonium hexa-fluoro titanate and $\mathrm{NiF}_{2}$ by liquid phase deposition technique. The addition of boric acid as an $F^{-}$scavenger will shift the equilibrium to one side and thereby deposition of the film is progressed. The rate of the reaction and the nature of deposition depend on growing time and temperature. The resultant films were characterized by XRD, EDAX, UV and SEM. The result shows that the deposited films have amorphous background, which becomes crystalline at $500^{\circ} \mathrm{C}$. The EDAX data confirms the existence of $\mathrm{Ni}$ atoms in $\mathrm{TiO}_{2}$ matrix. XRD analysis reveals the peaks corresponding to Ni but no peak of crystalline $\mathrm{NiO}$ was found. The transmittance spectra of $\mathrm{Ni}$ uniformly and non-uniformly doped $\mathrm{TiO}_{2}$ thin films show 'blue shift and red shift', respectively. Ni-doped $\mathrm{TiO}_{2}$ thin films can be used as photocatalyst for the photodegradation of methyl orange dye. It was found that, organic dye undergoes degradation efficiently in presence of non-uniformly Ni-doped $\mathrm{TiO}_{2}$ thin films when compared to uniformly doped films and pure $\mathrm{TiO}_{2}$ films under visible light. The photocatalytic activity increases with increase in the concentration of $\mathrm{Ni}$ in case of nonuniformly doped thin films but decreases with the concentration when uniformly doped thin films were used.
\end{abstract}

Keywords. $\mathrm{Ni- \textrm {TiO } _ { 2 }}$ thin film; LPD technique; photodegradation.

\section{Introduction}

In the field of photocatalysis, the polycrystalline system formed by transition metal-ion-doped $\mathrm{TiO}_{2}$ has been the object of several studies (Palmisano et al 1988; Soria et al 1991; Karakitsou and Verykios 1993; Choi et al 1994; Litter and Navio 1994, 1996). Transition metal ion doped $\mathrm{TiO}_{2}$ thin films have been prepared by a number of physical and chemical techniques by most of the researchers (Palmisano et al 1988; Choi et al 1994; Litter et al 1994; Sharma et al 2006), but liquid phase deposition technique has not been used yet. Using LPD technique, nano sized polycrystalline films can be prepared which is of great interest to tailor this material as efficient photocatalyst to meet the present environmental crisis.

Among the different transition metal ion dopants $\left(\mathrm{Fe}^{2+}\right.$, $\mathrm{Zn}^{2+}, \mathrm{Zr}^{2+}, \mathrm{Nd}^{3+}, \mathrm{Co}^{2+}, \mathrm{Ni}^{2+}$ etc), $\mathrm{Ni}^{2+}$ (Wang et al 1999; Park et al 2003; Jing et al 2005; Liu et al 2006; Noor Shahina Begum and Farveez Ahmed 2008) has been found to be an efficient dopant, as it possesses large surface area, crystallinity etc. On the other hand, low valence $\mathrm{Ni}^{2+}$ ion dopant improves the photocatalytic activity of certain semiconductor photocatalyst (Kudo and Sekizawa

*Author for correspondence (noorsb@rediffmail.com)
2000; Sreethawong et al 2005). The reason for this enhancement is still not so clear but it was explained that existence of low valence $\mathrm{Ni}^{2+}$ greatly suppressed recombination of electron hole pair on the surface of the catalyst (Wang 1999; Jing et al 2005; Yu et al 2006) and may also partially increase surface area of the films.

In our present study, we have successfully doped $\mathrm{Ni}^{2+}$ into the framework of $\mathrm{TiO}_{2}$ thin films through a simple novel technique known as LPD. The prepared film has been characterized by taking SEM, EDAX and XRD. Optical properties of doped and undoped films were compared. The photocatalytic behaviour of Ni-doped thin films was studied by applying it to methyl orange dye ( $\mathrm{Yu}$ et al 2006). It was found that $\mathrm{Ni}^{2+}$-doped $\mathrm{TiO}_{2}$ thin films played an important role in degradation of methyl orange dye.

More importantly, the existence of $\mathrm{Ni}^{2+}$ greatly suppressed recombination of electron-hole pairs on the surface of the photocatalyst. The presence of different oxidation states of dopants and a higher degree of crystallinity seems to be beneficial for retarding charge pair recombination processes in the $\mathrm{TiO}_{2}$ lattice, hence enhancing its activity. On the other hand, non-uniformly doped $\mathrm{Ni}-$ $\mathrm{TiO}_{2}$ exhibit high rate of photocatalytic activity when compared to uniformly doped $\mathrm{TiO}_{2}$ ( $\mathrm{Yu}$ et al 2006). 


\section{Experimental}

\subsection{Preparation of $\mathrm{Ni}$-doped $\mathrm{TiO}_{2}$ thin films}

The glass substrate after degreasing and cleaning ultrasonically, was placed vertically in a precursor of freshly prepared $0 \cdot 1 \mathrm{M}$ ammonium titanium fluoride and $0.2 \mathrm{M}$ boric acid solution. The saturated solution of nickel fluoride was then mixed with precursor of different proportions $(0.2,0.3$ and 0.5 at.\%). The experimental solution was kept at $30^{\circ} \mathrm{C}$ for about $20-40 \mathrm{~h}$. They were then removed and washed with double distilled water. The resultant film was homogeneous and dopant atoms were found to be distributed uniformly in the $\mathrm{TiO}_{2}$ matrix. The films thus obtained were annealed at different temperatures. The rate of deposition depends on temperature and concentration of the precursor solution. The thickness and quality of the film was greatly accelerated when the temperature and reaction time varied. Therefore, if the reaction was carried out at $40^{\circ} \mathrm{C}$ for $10 \mathrm{~h}$, the $\mathrm{Ni}$ dopant was distributed nonuniformly which can be confirmed by scanning electron micrographs (figures 3(c)-(d)).

\subsection{Photocatalytic degradation}

Ni-doped $\mathrm{TiO}_{2}$ thin film was placed in aqueous solution of methyl orange taken in glass beaker. The concentration of methyl orange was about $10 \mathrm{ppm}$. The solution was exposed to sun light at different irradiation times (10$80 \mathrm{~min}$ ). The solution was bubbled frequently with air during irradiation. The solution was scanned by UV-Vis spectrophotometer after every $10 \mathrm{~min}$ at the wavelength range from $300-1000 \mathrm{~nm}$ to measure the absorbance.

\section{Characterization of deposited films}

X-ray diffraction spectra were obtained from an X-ray diffractometer (type PW 3710 based tube anode: $\mathrm{Cu}$, $\mathrm{K} \alpha_{1}: 1.54056$ and $\left.\mathrm{K} \alpha_{2}: 1 \cdot 54439\right)$. Optical properties were studied by using UV-Vis-NIR, scanning spectrophotometer (type, Shimadzu-2003, Japan) in the wavelength range $300-1400 \mathrm{~nm}$. The structural properties and elemental analysis of coating were studied using scanning electron microscope and EDAX (type: Leica Cambridge Ltd./Leica S440i for SEM and Oxford link software for EDAX).

\section{Results and discussion}

\subsection{EDAX analysis}

The elemental analysis of Ni-doped $\mathrm{TiO}_{2}$ thin films was analysed by using electron diffraction X-ray analysis (EDAX). Figure 1 shows the EDAX spectra of Ni-doped $\mathrm{TiO}_{2}$ thin films deposited at $30^{\circ} \mathrm{C}$ and annealed at $500^{\circ} \mathrm{C}$.
The EDAX data confirmed that the film annealed at $500^{\circ} \mathrm{C}$ are nearly stoichiometric and indicates the peaks for $\mathrm{Ti}, \mathrm{O}_{2}$ and $\mathrm{Ni}$ atoms. This investigation also gave evidence that the Ni dopant is homogeneously distributed in the matrix of $\mathrm{TiO}_{2}$.

\subsection{Structure and surface morphology}

Figure 2 shows the XRD patterns for Ni-doped $\mathrm{TiO}_{2}$ thin films at different percentages of $\mathrm{Ni}$ and annealed at $500^{\circ} \mathrm{C}$. It can be seen that the samples show only anatase

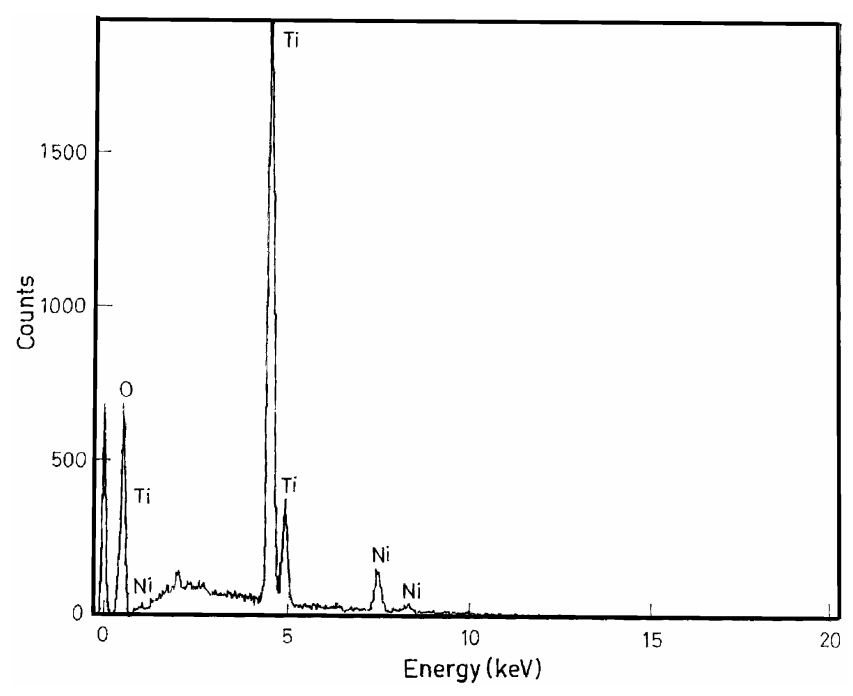

Figure 1. EDAX spectra of $\mathrm{TiO}_{2}$ thin film doped with 0.5 at. $\% \mathrm{Ni}$ and annealed at $500^{\circ} \mathrm{C}$

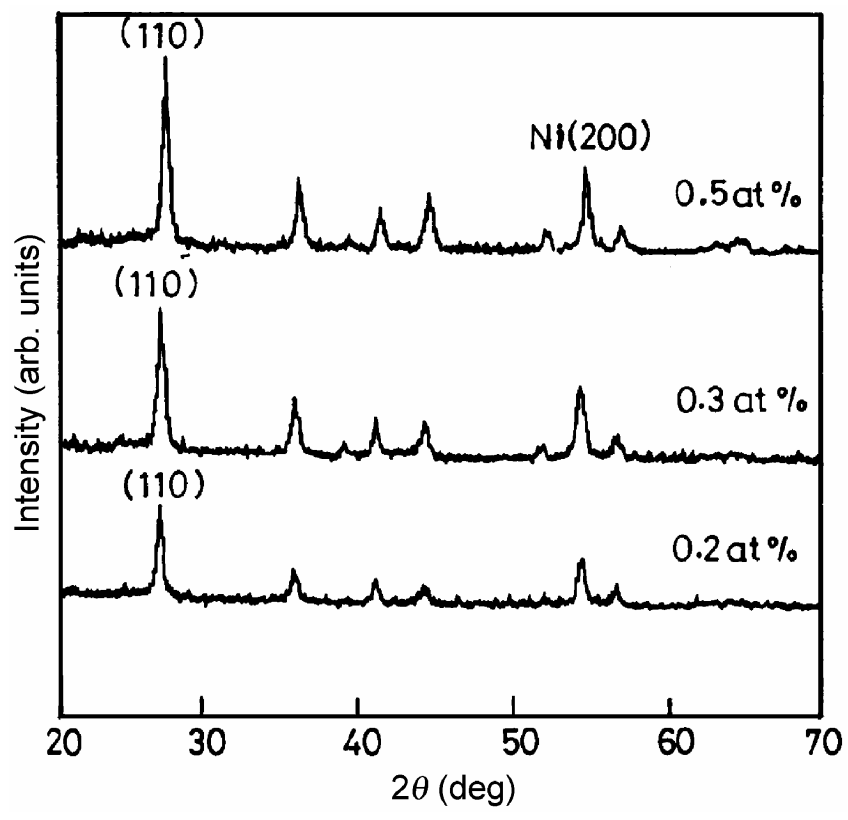

Figure 2. XRD pattern of $\mathrm{Ni}$ doped $\mathrm{TiO}_{2}$ thin films at different percentage of $\mathrm{Ni}$, annealed at $500^{\circ} \mathrm{C}$. 

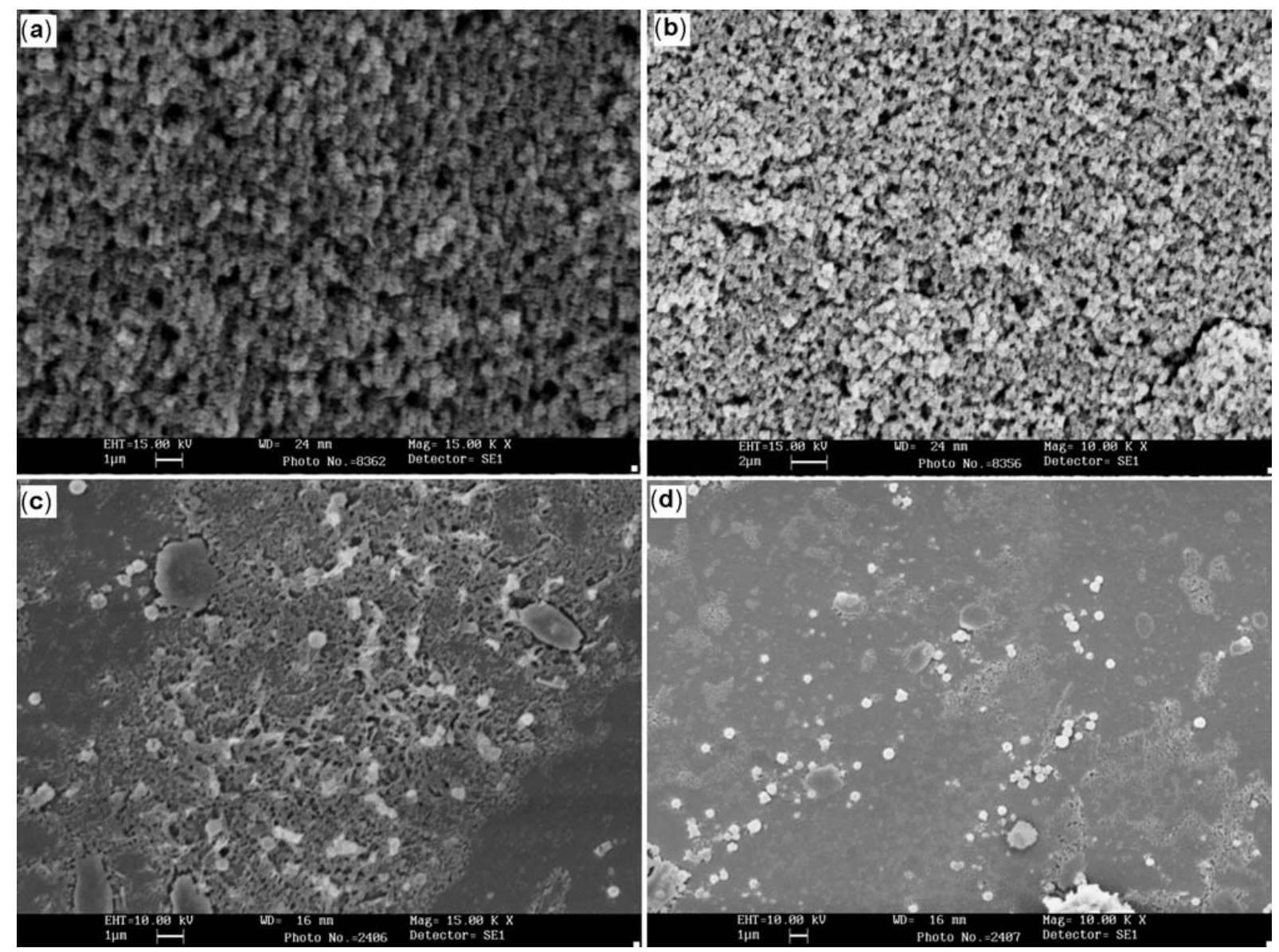

Figure 3. SEM of uniformly doped $\mathrm{Ni}-\mathrm{TiO}_{2}$ thin films (a) $0 \cdot 3 \% \mathrm{Ni}$, annealed at $500^{\circ} \mathrm{C}$, (b) $0.5 \% \mathrm{Ni}$, annealed at $500^{\circ} \mathrm{C}$ and SEM of non-uniformly doped $\mathrm{Ni}-\mathrm{TiO}_{2}$ thin films, (c) $0.3 \% \mathrm{Ni}$, annealed at $500^{\circ} \mathrm{C}$ and (d) $0.5 \% \mathrm{Ni}$, annealed at $500^{\circ} \mathrm{C}$

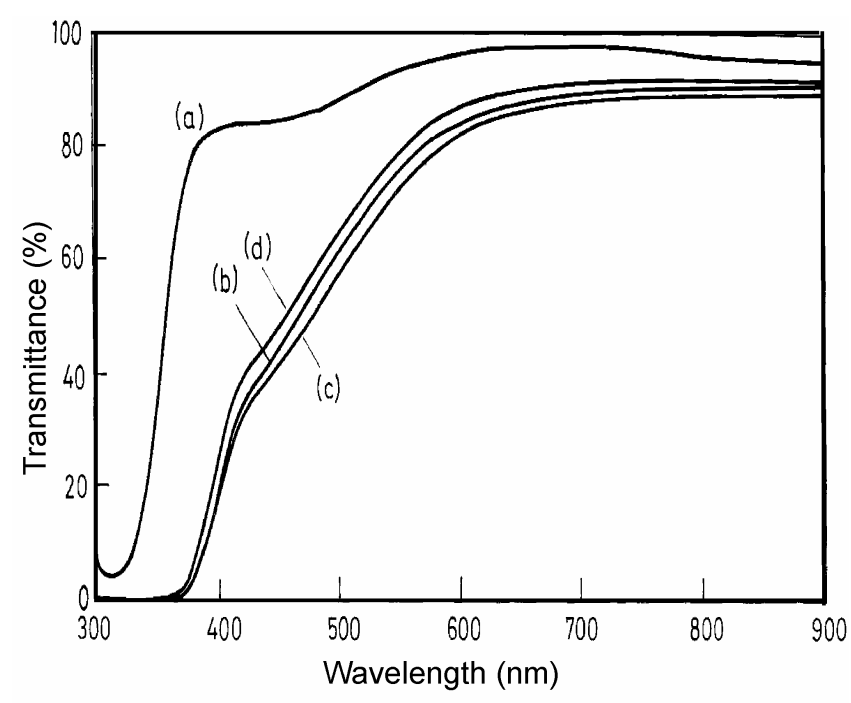

Figure 4. UV-visible transmittance spectra of Ni-doped $\mathrm{TiO}_{2}$ thin films: (a) bare $\mathrm{TiO}_{2}$ thin film, (b) non-uniformly doped $\mathrm{TiO}_{2}$ thin film with $0 \cdot 3$ at. $\% \mathrm{Ni}$, (c) non-uniformly doped $\mathrm{TiO}_{2}$ thin film with 0.5 at.\% $\mathrm{Ni}$ and (d) uniformly doped $\mathrm{TiO}_{2}$ thin film with 0.5 at. $\% \mathrm{Ni}$. phase regardless of Ni content. The mean size of the anatase crystallites in samples can be estimated by the line broadening of the XRD peak around $25 \cdot 3^{\circ}$ using the DebyeScherrer equation. No peaks corresponding to crystalline phase of $\mathrm{NiO}$ were found even at higher concentration of $\mathrm{Ni}\left(0.5\right.$ at.\%). It was observed that $\mathrm{Ni}^{2+}$ has an ionic radius similar to $\mathrm{Ti}^{4+}$ and can also form octahedral coordination as $\mathrm{Ti}^{4+}$ does (Nishikawa et al 2001).

Surface morphology of Ni-doped $\mathrm{TiO}_{2}$ thin films was studied by using Leica S440i scanning electron microscope with Oxford link software, used to evaluate surface topology of experimental films.

Figures 3(a)-(d) show scanning electron micrographs of uniformly and non-uniformly Ni-doped $\mathrm{TiO}_{2}$ thin films, with different concentrations of Ni-dopant $(0 \cdot 3$ and 0.5 at.\%) and annealed at $500^{\circ} \mathrm{C}$. Figures 3(a) and (b) show the compact structure with the segregation of $\mathrm{Ni}$ atoms uniformly in $\mathrm{TiO}_{2}$ matrix whereas figures 3(c) and (d) show the non-uniform distribution of $\mathrm{Ni}$ atoms in $\mathrm{TiO}_{2}$ framework. The average grain size is found to be $100-200 \mathrm{~nm}$ from scanning electron microscopic data. 


\subsection{Optical property}

Figure 4 shows UV-Vis transmittance spectra of Nidoped $\mathrm{TiO}_{2}$ thin film samples of different deposition modes at 350-900 wavelength range. Red shift was observed for non-uniformly doped $\mathrm{TiO}_{2}$ thin films at 0.5 at. $\% \mathrm{Ni}$ concentration, whereas for uniformly doped $\mathrm{TiO}_{2}$ thin films blue shift was viewed. It was also observed that as the concentration of dopant increases the absorption edge shifts to longer wavelength range $(0.3-0.5$ at. $\% \mathrm{Ni})$. For pure $\mathrm{TiO}_{2}$ no such changes were observed. From the above observation, it is concluded that $\mathrm{Ni}$ effects the bandgap of $\mathrm{TiO}_{2}$ (Liu et al 2001), but the effect varied from the doping mode. Figure 5 shows the bandgap calculation of nonuniformly doped $\mathrm{TiO}_{2}$ thin films. From the calculation the bandgap energy of 0.5 at.\% Ni-doped $\mathrm{TiO}_{2}$ thin films is $2.9 \mathrm{eV}$ against $3.2 \mathrm{eV}$ of the pure $\mathrm{TiO}_{2}$ thin films. The decrease of bandgap is the cause for red shift.

\subsection{Photodegradation studies}

Figure 6 shows that non-uniformly Ni-doped $\mathrm{TiO}_{2}$ exhibits photocatalytic activity much efficiently than uniformly Ni-doped $\mathrm{TiO}_{2}$ and pure $\mathrm{TiO}_{2}$ thin films in the visible region. It was found that methyl orange dye undergoes decolourization effectively in presence of nonuniformly doped $\mathrm{TiO}_{2}$ thin films with 0.5 at.\% Ni dopant when compared to 0.2 and 0.3 at.\% $\mathrm{Ni}$ dopant, whereas uniformly doped $\mathrm{Ni}-\mathrm{TiO}_{2}$ (figure 7) shows effective degradation with 0.3 at.\% $\mathrm{Ni}$ when compared to pure $\mathrm{TiO}_{2}$ thin films but the rate of degradation was very poor with 0.5 at. $\% \mathrm{Ni}$ dopant under visible region.

The photocatalytic activity was found to be strongly influenced by the amount of $\mathrm{Ni}$ and the mode of deposition. Hence, the mechanism for photocatalytic activity of different samples is attributed as their charge separation efficiency; this can be explained by $p-n$ junction theory (Yu et al 2006). The doped metallic ions may play a very important role in charge separation by capturing the electrons. In non-uniformly doped $\mathrm{TiO}_{2}$, thin films $\mathrm{Ni}^{2+}$ capture the electron that left freer hole at the bottom layer. Thus, the holes concentration increases at the bottom

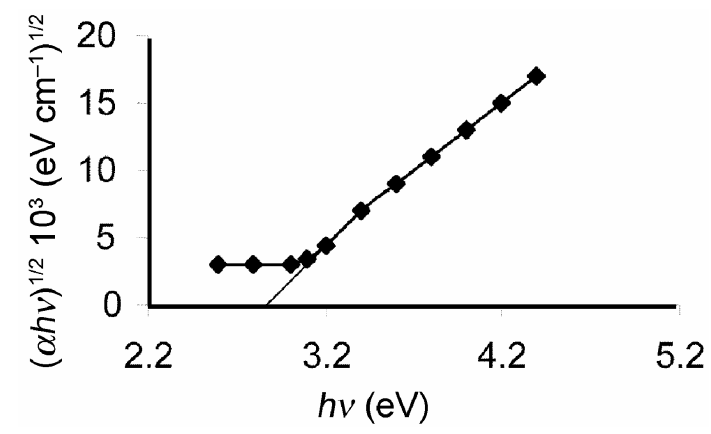

Figure 5. Bandgap energy of $\mathrm{TiO}_{2}$, non-uniformly doped with $\mathrm{Ni}(0.5$ at. \%). layer which migrates to surface layer by withdrawing the electrons from the surface. This results in the formation of inner electric field and creates $p-n$ junction. Thus $p-n$ junction barrier effectively (Liao et al 1995) prevented the recombination of electron-hole pair. It is also believed that non-uniformly doped $\mathrm{Ni}$ atom may partially increase the surface area of the film at an annealing temperature of $500^{\circ} \mathrm{C}$. Hence photodegradation predominates.

On the other hand, in uniformly doped $\mathrm{TiO}_{2}$ thin films, $\mathrm{Ni}^{2+}$ is uniformly depressed in the films. At high concentration the depressed $\mathrm{Ni}^{2+}$ becomes recombination centre that resists the generation of free charge carrier and hence photocatalytic activity is at its worst. But at low concentration, $\mathrm{Ni}^{2+}$ plays an important role in trapping the electrons and helps in charge separation, hence photocatalytic activity is comparatively good.

\section{Conclusions}

The thin films of Ni-doped $\mathrm{TiO}_{2}$ were prepared by a simple novel technique known as liquid phase deposition

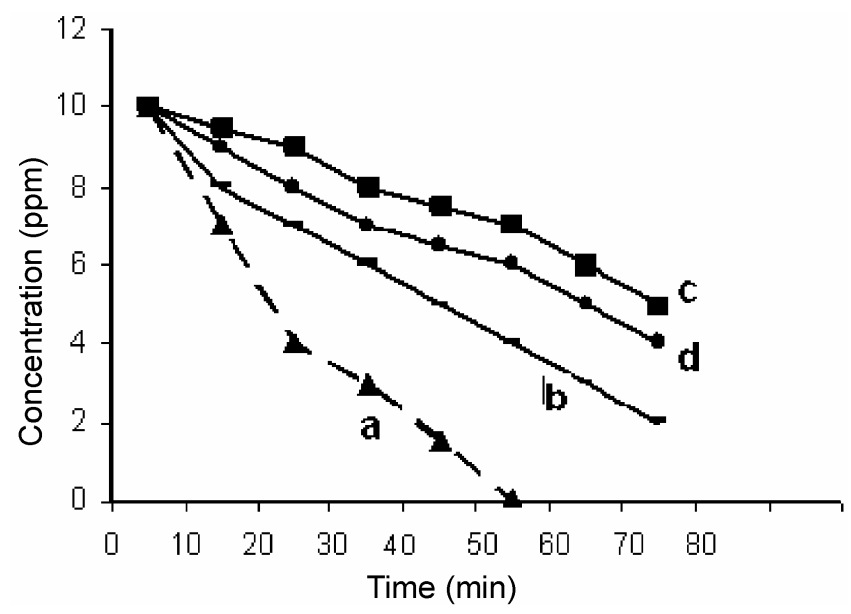

Figure 6. Photodegradation of methyl orange dye by nonuniformly doped $\mathrm{Ni}^{-\mathrm{TiO}_{2}}$ films: a. with $0.5 \%$ of $\mathrm{Ni}, \mathrm{b}$. with $0.3 \%$ of $\mathrm{Ni}$, c. with bare $\mathrm{TiO}_{2}$ and $\mathrm{d}$. with $0 \cdot 2 \% \mathrm{Ni}$.

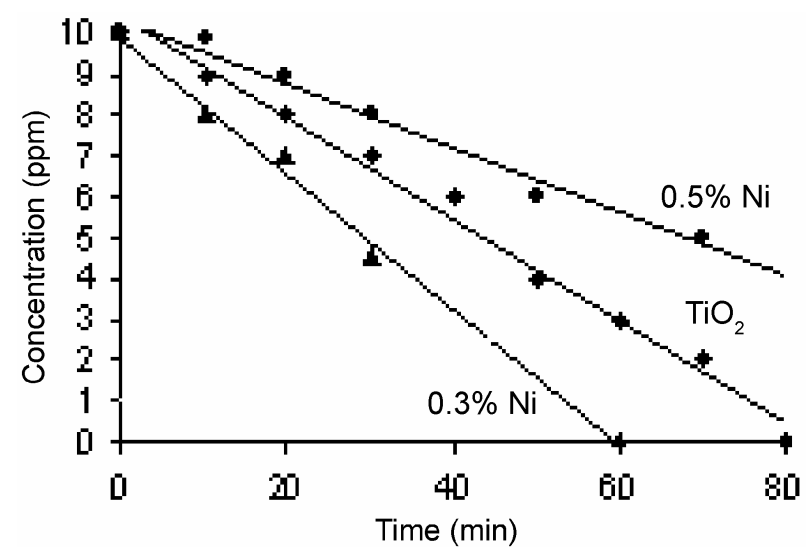

Figure 7. Photodegradation of methyl orange dye by uniformly doped $\mathrm{Ni}-\mathrm{TiO}_{2}$ films. 
technique. The mode of deposition can be altered by varying temperature and reaction time. As a result uniformly and non-uniformly doped $\mathrm{Ni}-\mathrm{TiO}_{2}$ thin films were formed. The prepared films were annealed at different temperatures and characterized by taking EDAX, XRD, SEM and UVvisible spectra.

An EDAX spectrum reveals the elementary composition of films and supports the existence of $\mathrm{Ni}$ atoms in the $\mathrm{TiO}_{2}$ matrix. XRD analysis shows the peak corresponding to $\mathrm{Ni}$ atom with the orientation [200]. Scanning electron micrographs describe the distribution of $\mathrm{Ni}$ atoms uniformly and non-uniformly in $\mathrm{TiO}_{2}$ matrix at different temperatures. The non-uniformly doped Ni shows remarkable improvement in photocatalytic activity of $\mathrm{TiO}_{2}$ thin films when compared to pure $\mathrm{TiO}_{2}$ and uniformly doped $\mathrm{TiO}_{2}$ thin films. The optimum concentration of nonuniformly doped $\mathrm{TiO}_{2}$ thin films is 0.5 at.\%.

\section{Acknowledgements}

The authors are grateful to Dr O M Hussain, SV University, Tirupati, for useful discussions and Mr D Basavaraj and Mr Kalyan Raj, BMS College of Engineering, Bangalore, for providing technical support.

\section{References}

Choi Wongyong, Termin A and Hoffermann M R 1994 J. Phys. Chem. 9813669
Jing Dengwei, Zhang Yaojun, Yan Wei and Guo Liejin 2005 Symposium on clean and green technologies for a sustainable environment, Honolulu, Hawaii, USA

Karakitsou E K and Verykios X E 1993 J. Phys. Chem. 971184

Kudo A and Sekizawa M 2000 Chem. Commun. 1371

Liao J D and Xu W J 1995 Photoelectricity technique (HangZhou: The Jiang University Press) p. 49

Litter M I and Navio J A 1994 J. Photochem. Photobiol. A Chem. 98183

Litter M I and Navio J A 1996 J. Mol. Catal. 106267

Liu Ch and Bao N Z 2001 Chin. J. Catal. 22204

Liu C, Tang X H, Mo C H and Wang J 2006 Huan Jing Ke Xue 272150

Nishikawa T, Nakajima T and Shinohara Y $2001 \mathrm{~J}$. Mol. Struct. (Theochem.) $\mathbf{5 4 5} 67$

Noor Shahina Begum and Farveez Ahmed HM 2008 Bull. Mater. Sci. 3143

Palmisano L, Augugliaro V, Sclafani A and Schiavello M 1988 J. Phys. Chem. 926710

Park Sangeun, Joo Hyunku, Kim Younggu and Jeon Myungseok 2003 Hwahak Konghak 41542

Sharma S D, Singh D, Saini K K, Chander Kant, Sharma Vikash, Jain S C and Sharma C P 2006 Appl. Catal. A314 40

Soria J, Conesa J C, Augugliaro V, Palmisano L, Schiavello M and Sclafani A 1991 J. Phys. Chem. 95274

Sreethawong T, Suzuki Y and Yoshikawa S 2005 Int. J. Hydrogen Energy 301053

Wang Yanqin, Hao Yanzhong, Cheng Humin, Ma Jiming and Xu Bin 1999 J. Mater. Sci. 342773

Yu Hua, Li Xin-Jun, Zheng Shao-Jian and Xu Wei 2006 Mater. Chem. \& Phys. 9759 